\section{The impact of fractured endodontic instruments on treatment outcome}

\author{
M. B. McGuigan, ${ }^{1}$ C. Louca ${ }^{1}$ and H. F. Duncan ${ }^{* 2}$
}

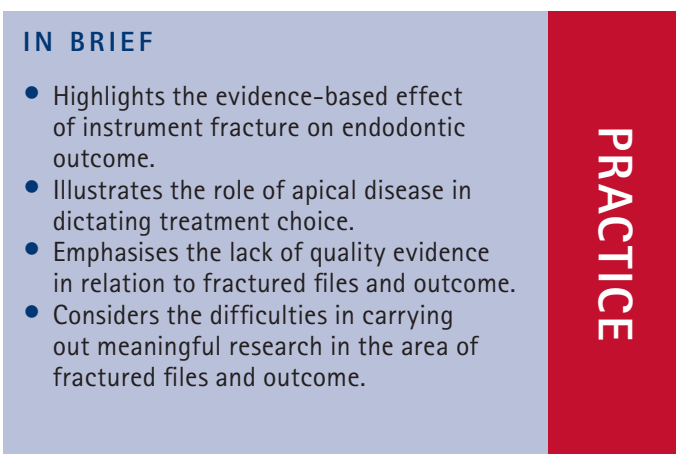

\begin{abstract}
Instrument fracture complicates the endodontic procedure by obstructing debridement, delaying treatment completion and affecting the patient's dental experience. When a file fractures there are several treatment options that could be selected, however, the future management should be based on the effect of the fractured instrument on treatment outcome. The aim of the following review was to analyse the literature assessing the impact of endodontic instrument fracture, focusing on its influence on endodontic prognosis and treatment outcome. A comprehensive MEDLINE search including various keywords identified several publications that considered the variables. Analysis of the publications highlighted a paucity of quality long-term clinical outcome studies relating specifically to the influence of instrument fracture. The available studies demonstrated a wide variety of methodologies reporting conflicting findings; therefore, meaningful conclusions were difficult. Within the confines of the literature it appears that retained fractured instruments do not reduce the prognosis of endodontically treated teeth if apical periodontitis is absent, however, if disease is present healing is significantly reduced. Therefore, the stage at which an instrument fractures in infected cases appears likely to be significant as canal disinfection will be compromised accordingly. Considering the risks associated with file removal, perhaps this should only be attempted if apical disease is present. Although it is accepted that the nature of file fracture precludes integration into randomised prospective trials, there is a need for well designed long-term outcome studies investigating the influence of fractured files.
\end{abstract}

\section{INTRODUCTION}

Evaluating the impact of fractured endodontic instruments ultimately involves careful analysis of how this procedural complication affects treatment outcome and prognosis. Understanding the manner in which fractured instruments influence outcome will guide clinical decision making and facilitate good patient communication, which is critical medico-legally. It is important to ascertain in which endodontic cases a fractured instrument is likely to affect success and identify others - if any - in which it may have a negligible effect. There are a limited number of recent studies specifically investigating

'Eastman CPD, UCL Eastman Dental Institute, 123 Gray's Inn Road, London, WC1X 8WD; ${ }^{2}$ Division of Restorative Dentistry and Periodontology, Dublin Dental University Hospital, Trinity College Dublin, University of Dublin, Dublin, Ireland

*Correspondence to: Henry F. Duncan

Email: Hal.Duncan@dental.tcd.ie; Tel: 0035316127356

\section{Refereed Paper}

Accepted 29 October 2012

DOI: 10.1038/sj.bdj.2013.271

${ }^{\circledR}$ British Dental Journal 2013; 214: 285-289 the influence of instrument fracture on the outcome of root canal treatment and retreatment, ${ }^{1,2}$ however, at present the literature is incomplete and extrapolation from general endodontic outcome studies is necessary. ${ }^{3-5}$

An awareness of the effect of fractured instruments on treatment outcome will direct future management; however, prevention of fracture, in addition to effective shaping and facilitation of chemo-mechanical disinfection, should be one of the principle aims of root canal instrumentation. It is the operator's professional responsibility to acquire training, competence and understanding of the current endodontic instrumentation techniques and materials. The advent of rotary nickel-titanium (NiTi) in endodontics ${ }^{6}$ signalled a new era in efficiency and cleaning/shaping techniques. These superelastic instruments were reported to reduce procedural errors such as transportation and ledging, producing more centred and rounded preparations. ${ }^{7,8}$ However, rotary NiTi instruments have also been perceived to have a higher risk of fracture than traditional stainless steel (SS) files. ${ }^{9}$ In addition, it has been reported that compared with SS instruments, NiTi files have a propensity to fracture without warning, with the resulting instrument fragments proving awkward to remove. ${ }^{10,11}$ Consequently, considerable research has been dedicated to NiTi instrument fracture, analysing the incidence of fracture, the mode of fracture and possible factors contributing to fracture including: instrument design, the manufacturing process, instrumentation techniques, the number of uses and the effects of sterilisation and the influence of canal morphology. ${ }^{12,13}$ Particular emphasis has been placed on the influence of operator proficiency and technique ${ }^{14,15}$ and as a result, practical prevention protocols have been published ${ }^{13}$ and new metallurgical innovations investigated ${ }^{16}$ with the intention of reducing the prevalence of fracture.

In the event of fracture the clinician has to be prepared to manage the situation both medico-legally and clinically. The decision to leave, ${ }^{17}$ bypass $^{13}$ or remove ${ }^{18}$ a fractured 
instrument should be made on the basis of a thorough knowledge of the success rates of each treatment option, balanced against potential risks of removal or file retention. Integration of microscopy into endodontic practice and advancements in specialised removal instruments and techniques have improved the clinician's ability to remove fractured files, however, removal may not always be possible or even desirable (Figs 1 and 2). Typically, the fractured fragment prevents access to the apical regions of the canal, which may or may not be infected. ${ }^{1,19}$ Therefore noting the stage of canal preparation during which the instrument fractured is particularly critical in infected cases.

The aim of this critical review was to systematically investigate the influence of the fragments on endodontic treatment, management and outcome. The evidencebase was analysed with a view to considering how clinical decision-making, treatment and prognosis alter as a result of a fractured instrument.

\section{SEARCH STRATEGY AND INCLU- SION OF PUBLICATIONS}

A MEDLINE search (PubMed) was conducted (up to December 2011) to identify all relevant studies using the following keywords: 'fractured instrument', 'broken instrument', 'separated instrument', 'fractured file', 'broken file' and 'separated file'. These key words were entered in combination with the MeSH major topic terms 'endodontics', 'dental pulp disease' and 'dental pulp test' to create a complex search strategy. The database search revealed 189 publications spanning from 1977-2011 (Table 1). In addition, bibliographies of all relevant papers and previous articles were manually searched revealing publications before 1977. Any relevant work published in the English language and presenting pertinent information related to the research title was considered for inclusion in the review.

The search produced 210 potential publications. Initially, all titles and abstracts were screened and the relevance to the impact of fractured instruments in endodontics was established. Secondly, if it was not possible to fully assess the relevance, full text analysis was performed. Finally, all relevant articles were analysed, if several publications from the same author were discovered, which commented on identical issues, the most relevant publication was selected. A final list of 171 publications was included in this review.

\section{FRACTURED INSTRUMENTS AND OUTCOME}

\section{Aim}

To fully understand the impact of fractured instruments on endodontic outcome it is imperative to briefly consider the success of standard endodontic procedures and in particular the reported influence of prognostic factors on outcome. This is the subject of the first of three reviews.

\section{General endodontic outcome}

In general de novo vital root canal treatment is reported to have greater than $90 \%$ success over a range of review periods.,20,21 Success in these studies usually refers to an absence of clinical signs and symptoms and no emergence radiographically of an apical radiolucency. ${ }^{22}$ However, certain studies have no clinical examination and rely only on radiographical analysis., ${ }^{3,21,23}$ The success of de novo treatment is reduced if there is preoperative evidence of apical periodontitis and root canal infection. ${ }^{21,24,25}$ In apical periodontitis cases, success generally refers to complete resolution of the apical radiolucency, ${ }^{22}$ however, other authors are less strict in their assessment of success. ${ }^{20}$ The reported success appears to drop further still if the root canal treatment is revised. ${ }^{26}$ The outcome of endodontic retreatment demonstrates conflicting data, ${ }^{5,27}$ however, it has been suggested that retreatment has a similar outcome to de novo treatment if the root canal morphology is not altered..$^{28}$ Conversely, if the morphology is altered the outcome drops significantly. ${ }^{27}$

Heterogeneity of data creates difficulties in comparing the plethora of studies investigating endodontic outcome and prognosis. ${ }^{29,30}$ The reported outcome of endodontic treatment differs due to inconsistencies in methodology, assessment criteria and level of evidence. ${ }^{26}$ The majority of studies are retrospective, ${ }^{31,32}$ a small number are prospective ${ }^{33,34}$ with a range of follow-up periods $^{3,20}$ and heterogeneity of success criteria $^{34,35}$ (Table 2). It is hoped with the advent of the consolidated standards of

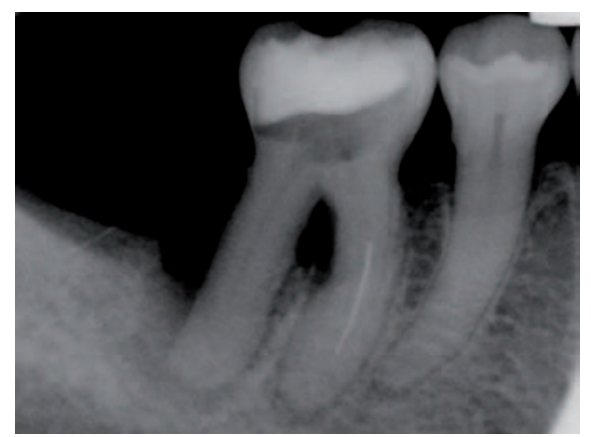

Fig. 1 Periapical radiograph of the mandibular right molar tooth with a fractured file in the mid-section of the mesial root

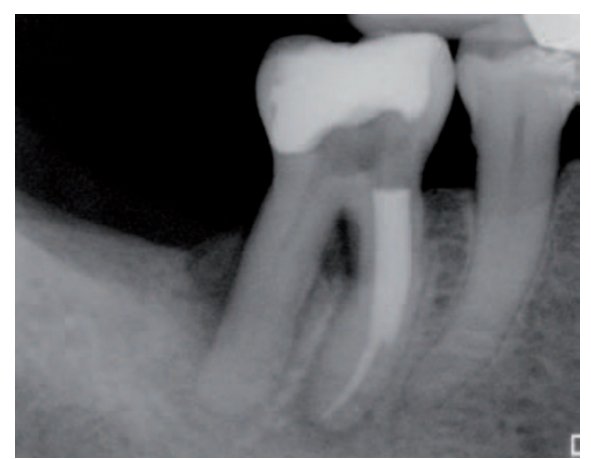

Fig. 2 Postoperative radiograph after removal of the fractured instrument and obturation of the mesial canals with gutta-percha. This postoperative 'check' radiograph was taken before placement of gutta-percha in the distal canal in order to verify the technical quality of the root canal obturation in the mesial root, before definitive restoration. Note the marked widening of the mesial preparation even after removal using ultrasonic tip and the operating microscope

reporting trials (CONSORT) guidelines that reporting of outcome may improve. These guidelines stipulate that when reporting a randomised clinical trial, two key elements are included: a flow-chart accounting for the journey of all patients (including drop outs) through the study and a standard checklist summarising the location of all key information in the manuscript. This standardised approach should create more homogenous data in the future, thereby improving the ease with which data can be compared and collated within systematic reviews. ${ }^{37}$ However, there may be a concern that the onerous nature of the CONSORT guidelines in the planning stages of randomised controlled trials may reduce further the number of such studies that are completed and published.

It is not within the remit of this study to carry out an exhaustive analysis of the evidence regarding the influence of various prognostic factors. It is important, 
Table 1 Search strategy through MEDLINE via PubMed (January 1977-December 2011)

\section{Command}

Endodontics [MeSH] OR Dental Pulp Disease [MeSH] OR Dental Pulp Test [MeSH]

Fractured Instrument OR Broken Instrument OR Separated Instrument OR Fractured File OR Broken File OR Separated File

Table 2 Summary of differing study characteristics of selected general endodontic outcome studies

\begin{tabular}{|c|c|c|c|c|c|}
\hline Author & Type of study & $\begin{array}{l}\text { Length of } \\
\text { review }\end{array}$ & $\begin{array}{l}\text { Measurements } \\
\text { of outcome }\end{array}$ & $\begin{array}{l}\text { Periapical } \\
\text { lesion } \\
\text { resolution }\end{array}$ & $\begin{array}{l}\text { Quality of } \\
\text { evidence } \\
(1-5)\end{array}$ \\
\hline Cvek et al. $1982^{35}$ & $\begin{array}{l}\text { Retrospective } \\
\text { cohort study }\end{array}$ & 4 years & $\begin{array}{l}\text { Radiographic } \\
\text { examination }\end{array}$ & Complete & 4 \\
\hline Sjögren et al. $1990^{3}$ & $\begin{array}{l}\text { Retrospective } \\
\text { cohort study }\end{array}$ & $8-10$ years & $\begin{array}{l}\text { Radiographic } \\
\text { examination }\end{array}$ & Complete & 4 \\
\hline Friedman et al. $1995^{20}$ & $\begin{array}{l}\text { Prospective } \\
\text { cohort study }\end{array}$ & 6-18 months & $\begin{array}{l}\text { Clinical and } \\
\text { Radiographic } \\
\text { examination }\end{array}$ & Complete & 2 \\
\hline Danin et al. $1996^{36}$ & $\begin{array}{l}\text { Randomised } \\
\text { controlled trial }\end{array}$ & 1 year & $\begin{array}{l}\text { Clinical and } \\
\text { radiographic } \\
\text { examination }\end{array}$ & Incomplete & 2 \\
\hline Sjögren et al. $1997^{33}$ & $\begin{array}{l}\text { Prospective } \\
\text { cohort study }\end{array}$ & 5 years & $\begin{array}{l}\text { Radiographic } \\
\text { examination }\end{array}$ & Complete & 3 \\
\hline Chugal et al. $2001^{31}$ & $\begin{array}{l}\text { Retrospective } \\
\text { cohort study }\end{array}$ & $3.5-4.5$ years & $\begin{array}{l}\text { Radiographic } \\
\text { examination }\end{array}$ & Complete & 4 \\
\hline Hoskinson et al. $2002^{32}$ & $\begin{array}{l}\text { Retrospective } \\
\text { cohort study }\end{array}$ & $4-5$ years & $\begin{array}{l}\text { Clinical and } \\
\text { radiographic } \\
\text { examination }\end{array}$ & Complete & 4 \\
\hline Farzaneh et al. $2004^{34}$ & $\begin{array}{l}\text { Prospective } \\
\text { cohort study }\end{array}$ & $4-6$ years & $\begin{array}{l}\text { Clinical and } \\
\text { Radiographic } \\
\text { examination }\end{array}$ & Complete & 3 \\
\hline \multicolumn{6}{|c|}{$\begin{array}{l}\text { NB: The quality of a clinical study can be assessed in various ways, with the Oxford Centre for Evidence-Based Medicine ranking a study (1-5) } \\
\text { within a 'level of evidence' pyramid. Classically a randomised controlled trial (RCT) or systematic review of RCTs would be ranked } 1 \text {, but may be } \\
\text { downgraded if not of high quality (in terms of numbers, follow-un period, recall drop out, desigin etct). Well designed trials that are not subject } \\
\text { to randomisation are generally ranked } 2 \text {, as can be well executed cohort and case-control studies. Other prospective case-control and cohort } \\
\text { studies are generally ranked } 3 \text {, as can well executed retrospective case-control studies. Case series studies would generally be ranked } 4 \text { as } \\
\text { would the majority of retrospective studies, while a case study or expert opinion would be considered level } 5\end{array}$} \\
\hline
\end{tabular}

however, to reach an overall conclusion as to the clinical significance of certain factors as this will assist in an analysis of the impact of fractured instruments on endodontic outcome. The general consensus appears to be:

- Preoperative apical periodontitis is the only consistently significant prognostic factor ${ }^{20,28,31,32}$

- Other factors such as the distance of the obturating material from the radiographic apex and the timely placement of a satisfactory permanent restoration are deemed to be important factors, especially with regard to retreatment. ${ }^{5}$ Therefore, by extrapolation, a retained fractured instrument will influence the apical extent of the root canal filling and hence may affect prognosis

- The significant prognostic factors for de novo endodontic and retreatment cases appear to be similar. ${ }^{4}$
In summary, apical periodontitis has been demonstrated to be a consistent prognostic factor and microorganisms have been shown to be the essential cause of persistent apical infection, ${ }^{38,39}$ therefore, any factor that compromises apical access - thereby hindering disinfection/debridement - will potentially have an impact on treatment outcome. Consequently, the type of case (vital or necrotic), the stage of treatment and the number of treatment visits are all likely to influence the level of infection in the root canal system and the possible sequelae of file fracture.

\section{Specific fractured file outcome}

A recent systematic review and metaanalysis analysed endodontic outcome when an instrument was retained in the root canal system. ${ }^{2}$ This review only considered de novo cases and concluded that a retained fractured instrument does not significantly reduce the prognosis of endodontic treatment in the absence of apical periodontitis, but that a fractured instrument in the presence of apical periodontitis did reduce prognosis. This corroborated several general outcome studies relating apical periodontitis and success. ${ }^{3,4,5}$ Notably, it was suggested that the influence of a fractured file on canal disinfection was slight, provided the treatment was carried out to the highest technical standard. ${ }^{2}$ What is difficult to establish from these studies is the additional influence of fractured files in teeth with apical periodontitis, as the presence of apical disease is already a negative prognostic factor. At present, the studies that address this issue do not contain large enough numbers to make meaningful conclusions. ${ }^{1,17}$

The aforementioned systematic review ${ }^{2}$ is based on only two case-control studies $^{1,17}$ dated 35 years apart. The lack of suitable studies is unfortunate and nullifies the scientific aim of such a review. Systematic reviews of randomised controlled trials are the highest level of evidence in medicine, comparing homogenous data from several prospective studies to enhance the 'power' of the results. Randomised controlled trials are uncommon in endodontics ${ }^{40}$ and they are impossible to conduct in the area of file fracture, where randomisation is impossible. Panitvisai and co-workers ${ }^{2}$ suggested that when investigating a procedural error, a case-control study is the highest level of evidence attainable and that the two included studies can be compared as treatment outcome has not significantly altered in 30 years. ${ }^{41}$ It should be recognised, however, that development with relation to instrumentation and technology has burgeoned over the same period. Furthermore, the included studies were carried out in dental hospitals and specialist practices, which are subpopulations; this may limit extrapolation to general dental practice.

Other studies have demonstrated that retained fractured instruments reduce prognosis. ${ }^{42,43}$ The first study published on the impact of retained fractured instruments reported a 19\% reduced healing rate when a fractured instrument was present. ${ }^{42}$ However, this study included only 15 fractured instrument cases and incomplete radiographic healing was classified as unsuccessful; however, the observation 
period was long at 4-10 years. Subsequent studies also reported a negative effect of a retained instrument fragment on endodontic outcome but only in the presence of a necrotic pulp ${ }^{43}$ or when a periapical lesion was present. ${ }^{27,44,45}$ These older studies, published before the introduction of NiTi files may have limited relevance to the current practice of endodontics. Recent publications have indicated that the presence of a preoperative apical radiolucency is a more significant prognostic factor than a fractured instrument per $s e^{1,12}$ although one study indicated that fractured instruments reduced the prognosis still further in the presence of apical radiolucency, this being attributed to compromised root canal disinfection. ${ }^{1}$ Finally, it can be logically extrapolated that as obturation of the root canal to within $0-2 \mathrm{~mm}$ of the radiographic apex has been significantly linked to an increase in the success of endodontic treatment ${ }^{3}$ and since a retained instrument is likely to prevent this, success will consequently be reduced, however, this has not been demonstrated conclusively in the literature.

It is evident that well designed trials investigating fractured instruments are rare as most studies suffer from insufficient patient numbers, poorly defined outcome parameters and subjective conclusions. ${ }^{12,46}$ In the future, it seems impossible that a suitable volume of cases can be identified from one clinic or specialist practice and therefore attention should be directed towards designing multi-centre trials involving several dental schools or specialist clinics working to an identical, agreed protocol. If this is carried out it may be possible to satisfactorily address a clinical question such as 'Do fractured instruments influence prognosis?' Or indeed as it has been reported that in vitro roots are weakened by dentine removal during instrument retrieval and are potentially at increased risk of vertical fracture ${ }^{47,48}$ another question may be 'Does removal of fractured instruments increase the clinical incidence of vertical fracture?'

\section{CONCLUSIONS}

If the root canal treatment is carried out to the highest technical standard, the retention of a fractured file in a tooth, with no evidence of apical periodontitis, does not significantly reduce prognosis.
However, if pre-existing apical periodontitis is evident a fractured file does significantly reduce healing of the lesion.

Therefore, although it is recommended that file removal should be attempted when possible, this does not appear to be evidence-based in the absence of apical disease.

The stage of treatment at which the file fractures has not been demonstrated to be significantly associated with treatment outcome; however, logic dictates that this is likely to be an important prognostic factor.

Due to a current shortage of clinical studies, there is a need for well designed long-term outcome studies investigating the influence of fractured files.

1. Spili P, Parashos P, Messer H H. The impact of instrument fracture on outcome of endodontic treatment. J Endod 2005; 31: 845-850.

2. Panitvisai $P$, Parunnit $P$, Sathorn $C$, Messer H H. Impact of a retained instrument on treatment outcome: a systematic and meta-analysis. J Endod 2010: 36: 775-780.

3. Sjögren U, Hagglund B, Sunqvist G, Wing K. Factors affecting the long-term results of endodontic treatment. J Endod 1990; 16: 498-504.

4. Ng Y-L, Mann V, Rahbaran S, Lewsey J, Gulabivala K. Outcome of primary root canal treatment: systematic review of the literature - Part 2. Influence of clinical factors. Int Endod J 2008; 41: 6-31.

5. Ng Y-L, Mann V, Gulabivala K. Outcome of secondary root canal treatment: a systematic review of the literature. Int Endod J 2008; 41: 1026-1046.

6. Walia H M, Brantley W A, Gerstein H. An initia investigation of bending and torsional properties of Nitinol root canal files. J Endod 1988; 14: 346-351.

7. Glosson C R, Haller R H, Dove S B, del Rio C E. A comparison of root canal preparations using $\mathrm{Ni}-\mathrm{Ti}$ hand, $\mathrm{Ni}$-Ti engine-driven, and $\mathrm{K}$-Flex endodontic instruments. J Endod 1995; 21: 146-151.

8. Haïkel $Y$, Serfaty $R$, Bateman $G$, Senger B, Alleman C. Dynamic and cyclic fatigue of engine-driven nickel-titanium rotary endodontic instruments. J Endod 1999; 25: 434-440.

9. Parashos P, Messer H H. Questionnaire survey on the use of rotary nickel-titanium endodontic instruments by Australian dentists. Int Endod J 2004; 37: 249-259.

10. Ward J R, Parashos P, Messer H H. Evaluation of an ultrasonic technique to remove fractured rotary nickel-titanium instruments from root canals: clinical cases. J Endod 2003; 29: 764-767.

11. Ankrum M T, Hartwell G R, Truitt J E. K3 Endo, ProTaper and ProFile systems: breakage and distortion in severely curved roots of molars. Int Endod J 2004; 30: 234-237.

12. Parashos $\mathrm{P}$, Messer $\mathrm{H} H$. Rotary NiTi instrument fracture and its consequences. J Endod 2006; 32: 1031-1043.

13. Cheung G S. Instrument fracture: mechanisms, removal of fragments, and clinical outcomes. Endod Topics 2009; 16: 1-26.

14. Yared G M, Kulkarni G K. Failure of ProFile Ni-Ti instruments used by an inexperienced operator under access limitations. Int Endod J 2002; 35: 536-541.

15. Parashos P, Gordon I, Messer H H. Factors influencing defects of rotary nickel-titanium endodontic instruments after clinical use. J Endod 2004; 30: 722-725.

16. Gutmann J L, Gao Y. Alterations in the inherent metallic and surface properties of nickel-titanium root canal instruments to enhance performance, durability and safety: a focused review. Int Endod J 2012: 45: 113-128.
17. Crump M C, Natkin E. Relationship of a broken root canal instruments to endodontic case prognosis: a clinical investigation. J Am Dent Assoc 1970; 80: 1341-1347.

18. Ruddle C J. Nonsurgical retreatment. J Endod 2004; 30: 827-845.

19. Lin $L M$, Rosenberg $P A$, Lin J. Do procedural errors cause endodontic treatment failure? J Am Dent Assoc 2005; 136: 187-193.

20. Friedman S, Löst C, Zarrabian M, Trope M. Evaluation of success and failure after endodontic therapy using a glass ionomer cement sealer. J Endod 1995; 21: 384-390.

21. Østavik D. Time-course and risk analyses of the development and healing of chronic apical periodontitis in man. Int Endod J 1996; 29: 150-155.

22. European Society of Endodontology. Quality guidelines for endodontic treatment; consensus report of the European Society of Endodontology. Int Endod J 2006; 39: 921-930.

23. Pettiette M T, Delano 0, Trope M. Evaluation of success rate of endodontic treatment performed by students with stainless-steel K-files and nickeltitanium hand files. J Endod 2001; 27: 124-127.

24. Smith C S, Setchell D J, Harty F J. Factors influencing the success of conventional root canal therapy - a five-year retrospective study. Int Endod J 1993. 26: 321-333.

25. Calişkan M K, Sen B H. Endodontic treatment of teeth with apical periodontitis using calcium hydroxide: a long-term study. Endod Dent Traumatol 1996; 12: 215-221.

26. Paik S, Sechrist C, Torabinejad M. Levels of evidence for outcome of endodontic retreatment. J Endod 2004; 30: 745-750.

27. Bergenholtz G, Lekholm U, Milthon R, Heden G, Odesjö B, Engström B. Retreatment of endodontic fillings. Scand J Dent Res 1979; 87: 217-224.

28. Gorni F G, Gagliani M M. The outcome of endodontic treatment: a 2-yr follow-up. J Endod 2004; 30: 1-4.

29. Sackett D L, Rosenberg W M, Gray J A, Haynes R B, Richardson W S. Evidence based medicine: what it is and what it isn't. BMJ 1996; 13: 71-72.

30. Ng Y-L, Mann V, Rahbaran S, Lewsey J, Gulabivala K. Outcome of primary root canal treatment: systematic review of the literature - part 1. Effects of study characteristics on probability of success. Int Endod J 2007; 40: 921-939.

31. Chugal N M, Clive J M, Spångberg L S. A prognostic model for assessment of the outcome of endodontic treatment: effect of biologic and diagnostic variables. Oral Surg Oral Med Oral Pathol Oral Radiol Endod 2001: 91: 342-352.

32. Hoskinson S E, Ng Y L, Hoskinson A E, Moles $D R$, Gulabivala K. A retrospective comparison of outcome of root canal treatment using two different protocols. Oral Surg Oral Med Oral Pathol Oral Radiol Endod 2002; 93: 705-715.

33. Sjögren U, Figdor D, Persson S, Sundqvist G. Influence of infection at the time of root filling on the outcome of endodontic treatment of teeth with apical periodontitis. Int Endod J 1997; 30: 297-306.

34. Farzaneh M, Abitbol S, Friedman S. Treatment outcome in endodontics: the Toronto study. Phases I and II: orthograde retreatment. J Endod 2004; 30: 627-633.

35. Cvek M, Granath L, Lundberg M. Failures and healing in endodontically treated non-vital anterior teeth with posttraumatically reduced pulpal lumen. Acta Odontol Scand 1982; 40: 223-228.

36. Danin J, Strömberg T, Forsgren $H$, Linder $L E$, Ramsköld L O. Clinical management of nonhealing periradicular pathosis. Surgery versus endodontic retreatment. Oral Surg Oral Med Oral Pathol Oral Radiol Endod 1996; 82: 213-217.

37. Hargreaves K M. From consent to CONSORT: clinical research in the 21st century. J Endod 2005; 31: 1-3.

38. Nair P N, Sjögren U, Figdor D, Sundqvist G Persistent periapical radiolucencies of root-filled human teeth, failed endodontic treatments and periapical scars. Oral Surg Oral Med Oral Pathol Oral Radiol Endod 1999; 87: 617-627.

39. Siqueira J F Jr. Aetiology of root-canal treatment failure: why well treated teeth can fail. Int Endod J 
2001; 34: 1-10.

40. Spångberg L S. Systematic review in endodontics examples of GIG0? Oral Surg Oral Med Oral Pathol Oral Radiol Endod 2007; 103: 723-724.

41. Friedman $S$. Expected outcomes in the prevention and treatment of apical periodontitis. In Ørstavik $D_{\text {, }}$ Pitt Ford T (eds) Essential endodontology: prevention and treatment of apical periodontitis. 2nd ed. pp 408-469. Oxford: Blackwell Munksgaard, 2008.

42. Strindberg $L Z$. The dependence of the results of pulp therapy on certain factors: an analytical study based on radiographic and clinical follow-up examination. Acta Odontol Scand 1956; 14: 1-175.

43. Kerekes $K$, Tronstad L Long-term results of endodontic treatment performed with a standardized technique. J Endod 1979; 5: 83-90.

44. Grossman L I. Guidelines for the prevention of fracture of root canal instruments. Oral Surg Oral Med Oral Pathol 1969; 28: 746-752.

45. Fox J, Moodnik R M, Greenfield E, Atkinson J S. Filling root canals with files: radiographic evaluation of 304 cases. NYState Dent J 1972; 38: 154-157.
46. Fu M, Zhang Z, Hou B. Removal of broken files from root canals by using ultrasonic techniques combined with dental microscope: a retrospective analysis of treatment outcome. J Endod 2011; 37: 619-622.

47. Souter N J, Messer H. Complications associated with fractured file removal using an ultrasonic technique. J Endod 2005; $31:$ 450-452.

48. Madarati A A, Qualtrough A J, Watts D C. Vertical fracture resistance of roots after ultrasonic removal of fractured instruments. Int Endod J 2010: 43: 424-429.

\section{Corrigendum}

General article (BDJ 2013; 214: 123-125)

In the above article, the surname of the dental historian Ronald Cohen (and his wife Muriel) is misspelt throughout as 'Cohan'. The correct spelling is 'Cohen'.

In Figure 1 in the same article, the correct labelling of the three people depicted in the photo are, from left to right, Professor Nairn Wilson, Dr Stuart Robson and Dr Margaret Wilson.

The author apologies for any inconvenience that may have been caused. 